\title{
A Pós-Verdade, Para Além do Verdadeiro e do Falso
}

\author{
António Guerreiro \\ antoniofguerreiro@googlemail.com
}

DOI $10.2478 / \mathrm{kjps}-2020-0010$

Em 2016, uma palavra que não era nova mas teve nesse ano um enormíssimo aumento de ocorrências e deixou de ser de uso estrito foi consagrada como "palavra internacional do ano" pelo Oxford Dictionaries, o departamento da Universidade de Oxford que se ocupa da elaboração de dicionários da língua inglesa (e não só) e é a máxima autoridade, em Inglaterra, nos assuntos lexicais: a palavra "pós-verdade". Segundo os investigadores responsáveis do dicionário, a palavra tinha sido usada pela primeira vez em 1992, num ensaio do dramaturgo e romancista servoamericano Steve Tesich, publicado no jornal norte americano The Nation, com um sentido temporal inteiramente legitimado pela preposição "pós". Ora, o alcance semântico da palavra - agora tornada canónica por um dicionário dito "a mãe de todos dos dicionários" - vai para além, ou até ignora, esse sentido temporal (não pode ser entendida por analogia com "pós-guerra", por exemplo), indicando antes a ideia de que a verdade se tornou irrelevante, eclipsou-se: no sentido agora fixado, pós-verdade não é o que vem depois da emergência da verdade, mas o que é indiferente a ela. 
Dois acontecimentos tinham potenciado nesse ano a expansão e a cristalização da palavra enquanto novo conceito: o referendo em Inglaterra em que os defensores do Brexit obtiveram a maioria; e, alguns meses mais tarde, a eleição de Donald Trump para a presidência dos Estados Unidos. Um fenómeno tinha emergido nesses dois momentos, em ambos os lados do Atlântico: tanto na campanha do candidato Trump como na do Brexit o método de persuasão dos eleitores consistiu em difundir no espaço público afirmações e dados que eram falsos, mas a denúncia da sua falsidade tornara-se ineficaz, o chamado fact-checking não tinha efeitos práticos, não anulavas as falsidades porque se tornaram extremamente porosas as fronteiras entre a verdade e a mentira, a diferença entre o verdadeiro e o falso tinha-se tornado não-essencial. Nestas condições, triunfou uma nova realidade que ganhou o nome paradoxal - mas perfeitamente plausível sob as novas condições em que se dá o surgimento de uma "nova realidade" - de "factos alternativos". As fake news, essa categoria que invadiu entretanto o discurso sobre os novos media, são notícias sobre as quais pouco importa exercer um desmentido porque elas são instrumentos de uma lógica que não concede importância à distinção entre o verdadeiro e o falso. Uma vez eleito, Donald Trump não alterou em nada o seu discurso, tendo elevado à condição oficial (tanto no pano político interno como no plano das relações com o resto do mundo) os dispositivos retórico-pragmáticos da pós-verdade.

A condição pós-verdade ofereceu-se em toda a sua evidência nesses dois grandes acontecimentos de 2016 e no que se seguiu a eles. Recentes, são também os conceitos analíticos que permitem descrever o seu funcionamento. Mas ela tem uma existência mais antiga e prenunciada por manifestações menos relevantes e menos conspícuas (por exemplo, o modo como foram negadas ou escondidas algumas descobertas científicas, desde a relação do tabaco com o cancro ao aquecimento global provocado por acção antropogénica). A Internet e as chamadas redes sociais não podem deixar de ser evocadas enquanto causas imediatas - mas não exclusivas - desta nova condição, muito embora seja indispensável perceber que deter a bomba 
atómica não significa fazê-la explodir apenas porque ela está à mão, à disposição dos caprichos. O surgimento e difusão planetária da Internet e dos media sociais (recordemos que o Facebook foi criado em 2004) ditou o declínio dos media tradicionais. Estas novas fontes de informação e meios de difusão não tornaram apenas imediata, espantosamente veloz e subtraída a qualquer controlo editorial a circulação de notícias e de dados; tornaram também muito pouco nítida a diferença entre notícias e opinião - uma diferença que se tinha tornado regra canónica nos jornais e em todos os media ditos de referência. Importa, no entanto, lembrar que a história do jornalismo situa por volta da terceira década do século XIX o momento em que a ideia de objectividade se torna uma questão importante. $O$ viés, o preconceito e a parcialidade eram até então uma marca inquestionada dos meios noticiosos impressos.

Mas seria errado dizer que essa falta de objectividade é um equivalente, embora numa dimensão incomparável à escala da sociedade mediática do nossos tempo, daquilo a que chamamos hoje fake news. O que caracteriza as fake news, como observou Lee Mcintyre, autor de um livro sobre a pós-verdade, é o facto de elas não serem apenas falsas, mas serem criadas com o propósito de introduzir a falsidade, sendo portanto deliberadamente, intencionalmente, falsas ${ }^{1}$. A antiga questão da objectividade e da subjectividade, da parcialidade e da imparcialidade, perde toda a pertinência. E até a verdade e a mentira como critério de classificação das notícias perde a sua antiga validade incontestável porque estamos agora confrontados com outro tipo de falsidade, como fica explícito de maneira eloquente nos "factos alternativos" que alimentam as fake news. São alternativos os factos que não se limitam a ser falsos, a não coincidir com a realidade, mas vão mais além: desafiam a realidade. Também não precisam de recorrer aos protocolos e processos de verosimilhança porque se situam num plano que não é o da simples ficção.

${ }^{1}$ Lee Mcintyre, Post-truth, MIT Press, Cambridge, Massachussets, 2018, págs. 112-113. 
Num célebre ensaio intitulado "Truth and Politics", que constitui um dos oito capítulos de Between Past and Future, Hannah Arendt empreende uma longa reflexão sobre o velho e complicada conflito entre verdade e política, sobre essa tensão que Platão quis resolver através da figura do filósofo-rei, encarnação de uma política filosófica em nome do primado da verdade. Logo no primeiro parágrafo desse ensaio, a autora explicita com enorme clareza os caminhos que se propõe percorrer: "O objecto destas reflexões é um lugar comum. Nunca constituiu dúvida para ninguém que a verdade e a política não se dão bem (...). As mentiras sempre foram consideradas como utensílios necessários e legítimos, não apenas do ofício de político ou de demagogo, mas também do ofício de homem de Estado"². E poucas linhas à frente, como corolário destas afirmações, lança a pergunta: "Faz parte da própria essência da verdade ser impotente e da própria essência do poder ser enganador?". Para Hananh Arendt as opiniões só são legítimas quando se baseiam nas "verdades de facto". São essas verdades que a informação deve, acima de tudo, garantir. Há em Platão um antagonismo entre verdade e opinião que serve de referência a Hannah Arendt e a leva a acrescentar que tal antagonismo se prolonga (especialmente no Górgias) num outro antagonismo "entre a comunicação sob forma de 'diálogo', discurso apropriado à verdade filosófica, e sob a forma de 'retórica', através da qual o demagogo, como diríamos hoje, persuade a multidão"3.

É óbvio que no horizonte de Hannah Arendt nada anunciava - nem podia anunciar - esses componentes da pós-verdade que são os "factos alternativos". O que no seu pensamento se aproxima de algum modo destas fabricações que rasuram as fronteiras entre a verdade e a mentira, é o negacionismo, que abole ou falsifica a realidade, mesmo perante aqueles que a testemunharam. O caso clássico é o da negação do extermínio à escala industrial montada pelo regime nazi: os

\footnotetext{
2 Hannah Arendt, Between Past and Future. Eight Exercises in Political Thought, New York, Viking Press, 1968, pág . 227.

3 Idem, pág. 234. 
negacionistas aproveitaram o facto de o processo ter sido concebido com o objectivo de não deixar rasto para pedirem provas da sua existência. Mas é também a sua caracterização das sociedades totalitárias que se tem prestado a uma leitura que vê aí o anúncio daquilo a que mais de meio século depois ganha o nome de pósverdade. Numa passagem das últimas páginas desse ensaio sobre a relação entre verdade e política, podemos ler: "De uma substituição coerente e total da verdade de facto por mentiras não resulta que as mentiras passem a ser aceites como verdades, nem que a verdade seja difamada como mentira. O que resulta daí é que o sentido pelo qual nós nos orientamos no mundo real - e a categoria da verdade em oposição à falsidade é um dos meios mentais que nos dá esse sentido de orientação - se encontra destruído ${ }^{4}$. E, no seu ensaio sobre o sistema totalitário, Hannah Arendt definiu a ideologia como "a lógica de uma ideia" que traz consigo "a vontade de cumprimento total" e cumpre-a fazendo com que tudo se conforme à lógica dessa ideia. Parece ser possível deduzir destas afirmações um efeito que é também o da pós-verdade: o verdadeiro e o falso deixam de ser categorias operatórias. E veja-se como sob o regime da pós-verdade se multiplicam as teorias da conspiração, se põem a circular as mais desvairadas explicações para todos os fenómenos (sejam eles o Covid-19 ou o aquecimento global) que recorrem às narrativas do complot.

A ideologia, no sentido de Hannah Arendt, parece ser o alimento mais próprio daquilo que nos regimentos totalitários ficou conhecido com o nome de "propaganda". Mas serão então as fake news um novo nome para o que dantes se chamava propaganda? Lee Mcintyre, no livro já citado, discute esta questão recorrendo aos argumentos apresentados por Jason Stanley, num livro que se intitula How Propaganda Works. Um dos argumentos fundamentais é o de que a propaganda não deve ser confundida com a comunicação enviesada ou mesmo manipuladora. A propaganda, diz Mcintyre seguindo o livro de Stanley, não é necessariamente uma tentativa de convencer alguém acerca de algo que não é 
verdade, nem devemos pensar que todas as afirmações propagandistas são destituídas de sinceridade. Pelo contrário, a propaganda pode ser definida como um meio de explorar e fortalecer a ideologia, de a tornar um instrumento sem falhas. $\mathrm{O}$ objectivo da propaganda, tal como Stanley a define, não consiste em convencer alguém de que o propagandista está certo e tem razão, mas em demonstrar que ele tem autoridade sobre a própria verdade. Quando um líder político é realmente poderoso, ele pode desafiar a realidade. E, neste ponto, Stanley cruza-se obviamente com Hannah Arendt, para quem "o que convence as massas não são os factos, nem mesmo factos inventados, mas antes o aberto desafio".

Seguindo estes argumentos, o fenómeno actual das fake news, das actuais sociedades democráticas, mostra afinidades óbvias - embora passíveis de se revelarem muito mais complexas do que parecem à primeira vista - com a propaganda dos regimes totalitários. Ora, a hipótese de uma tal coincidência, ainda que cheia de complexidades, foi contestada num livro recente por uma filósofa francesa, leitora de Hannah Arendt, chamada Myriam Revault D'Allonnes. Esse livro tempo por título La Faiblesse du vrai. Ce que la post-vérité fait à notre monde comum $^{5}$. O seu ponto de partida é precisamente o fenómeno a difusão de um discurso, do qual faz parte as fake news, que abole a distinção entre o verdadeiro e o falso, fazendo triunfar um relativismo que, evidentemente, constitui um desafio enorme para as nossas democracias. Reconhecer que deixou de ser operatória a divisão entre o verdadeiro e o falso não significa que se está a caracterizar a nossa época como a da mentira generalizada. As coisas, como demonstrámos até aqui e toda a argumentação desenvolvida por Myriam Revault D'Allonnes confirma, são muito mais complicadas. A questão justifica e torna até muito pertinente um longo percurso como aquele que faz a autora deste livro, que se detém nalgumas estações obrigatórias: Platão e os Gregos, passando por Maquiavel (o momento moderno onde se acentua a distância entre verdade e política), e, mais perto de nós, os

\footnotetext{
5 Éditions du Seuil, Paris, 2018.
} 
"filósofos da suspeita" (Marx, Nietzsche e Freud). A proposição nietzschina de que não há factos mas apenas interpretações surge aqui como passível de ser interpretada como percursora da pós-verdade. Mas o perpectivismo nietzschiano, como mostra a autora de La Faiblesse $d u$ vrai, não é passível de ser lido como equivalente do que se passa nesta nossa época da pós-verdade. Outros pretendem que foi o pós-modernismo que liquidou a antiga autoridade que a verdade detinha e conduziu ao triunfo da pós-verdade. Mas estes caminhos directos, traçados com demasiada simplicidade, são enganosos e não levam muito longe. Não é por aí, nem pouco mais ou menos, que segue Miriam Revault D’Allonnes, que, num aparte do seu livro, analisa a pós-verdade na sua diferença em relação à mentira ideológica das sociedades totalitárias. E é neste ponto que importa seguir o seu pensamento porque ele esclarece de certa maneira o que ficou em suspenso quando, atrás, falámos da relação entre pós-verdade e propaganda. A visão desta filósofa francesa é a de que nos sistemas totalitários cria-se um mundo falso, de mentira, através de uma ideologia dotada de uma coerência sistemática que faz do real uma ficção impermeável a tudo o que a possa contrariar. O processo absolutamente lógico e coerente pelo qual os sistemas totalitários fornecem um sistemas de explicação da vida e do mundo não se assemelha aos instrumentos da pós-verdade. Estes últimos têm muito mais a ver com processos de difusão que as redes e os novos media promovem e potenciam. Neste sentido, a mentira ideológica é ainda uma peça da engrenagem da política moderna, em que a ideologia, no sentido que lhe dá Hannah Arendt, se torna capaz de criar um mundo completamente fictício. Já a pós-verdade apresenta-se com um aspecto diferente: resulta de um relativismo generalizado, da dissolução das verdades de facto no fluxo crescente das opiniões. Em vez da ideologia, temos agora uma pragmática que configura, na sua indiferença à verdade, a política da pós-verdade, tenha ela as roupagens do populismo ou de um autoritarismo que evoca alguns traços do velho fascismo. 